\title{
Additive Manufacture of Cellulose Based Bio-Material on Architectural Scale
}

\author{
Yimeng Wei ${ }^{1,2(\otimes)}$, Areti Markopoulou ${ }^{1}$, Yuanshuang $\mathrm{Zhu}^{2}$, \\ Eduardo Chamorro Martin ${ }^{1}$, and Nikol Kirova ${ }^{1}$ \\ ${ }^{1}$ Institute for Advanced Architecture of Catalonia, Barcelona, Spain \\ yimeng.wei@iaac.net \\ 2 Shanghai Digital Fabrication Engineering Technology Center, Shanghai, China
}

\begin{abstract}
There are severe environmental and ecological issues once we evaluate the architecture industry with LCA (Life Cycle Assessment), such as emission of $\mathrm{CO}_{2}$ caused by necessary high temperature for producing cement and significant amounts of Construction Demolition Waste (CDW) in deteriorated and obsolete buildings. One of the ways to solve these problems is Bio-Material. CELLULOSE and CHITON is the 1st and 2nd abundant substance in nature (Duro-Royo, J.: Aguahoja_Programmable Water-based Biocomposites for Digital Design and Fabrication across Scales. MIT, pp. 1-3 (2019)), which means significantly potential for architectural dimension production. Meanwhile, renewability and biodegradability make it more conducive to the current problem of construction pollution. The purpose of this study is to explore Cellulose Based Biomaterial and bring it into architectural scale additive manufacture that engages with performance in the material development, with respect to time of solidification and control of shrinkage, as well as offering mechanical strength. At present, the experiments have proved the possibility of developing a cellulose-chitosan- based composite into 3D-Printing Construction Material (Sanandiya, N.D., Vijay, Y., Dimopoulou, M., Dritsas, S., Fernandez, J.G.: Large-scale additive manufacturing with bioinspired cellulosic materials. Sci. Rep. 8(1), 1-5 (2018)). Moreover, The research shows that the characteristics (Such as waterproof, bending, compression, tensile, transparency) of the composite can be enhanced by different additives (such as xanthan gum, paper fiber, flour), which means it can be customized into various architectural components based on Performance Directional Optimization. This solution has a positive effect on environmental impact reduction and is of great significance in putting the architectural construction industry into a more environment-friendly and smart state.
\end{abstract}

Keyword: Chitosan · Cellulose · Biomaterial · Performance directional optimization $\cdot$ Robotic construction $\cdot$ Additive manufacture

\section{Methodology and Proposal}

\subsection{Methodology_A Multi-Scalar Approach}

This thesis will conduct material research and testing from three different levels: MICRO - MESO - MACRO, and finally applied to architectrual-scale application [4]. 
The MICRO research will focus on the microstructure of the crystallization reaction of chitosan-cellulose mixed materials, as well as the intermolecular reaction of other additives.

The MESO research will focus on the testing of various properties of the mixed material, including the mechanical properties of the dried sample and the printability of the mixed material in wet state.

The MACRO research, new structural forms suitable for additive manufacturing and robotic construction will be studied, and cellulose-chitosan based bio-material will be used to complete architectural-scale printing work (Figs. 1, 2, 3).

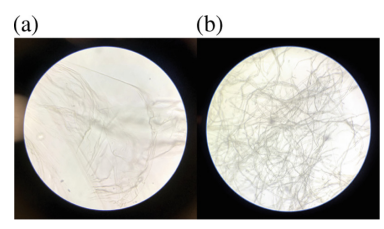

Fig. 1. MICRO:

Intermolecular Mechanism and Reaction: (a) Cellulose with chitosan (1 $\mathrm{g}$ chi in $1 \%$ w/w acetic acid). (b) Paper fiber with chitosan (1g chi in $1 \%$ w/w acetic acid).

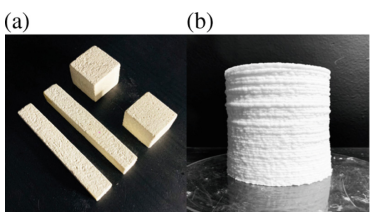

Fig. 2. MESO: Material Innovation and Properties experiments: (a) Sample of Chitosan-Cellulose based Biomaterial in the dry state. (b) 3D-Printing accumulation test of Chitosan-Cellulose based Biomaterial.

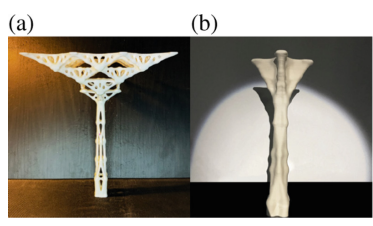

Fig. 3. MACRO:

Architecture and Structure Design: (a) Pillar structure design according to BESO analysis. (b) $1 \mathrm{~m}$ high 3D-Printing structure with Cellulose based Biomaterial.

\subsection{Proposal}

Starting from the current issues in the construction industry, to the current academic research ideas in each field, it is not difficult to find an intersection: based on new materials (such as bio-materials), grafted to new productivity (Robotic Construction), and new construction methods (Additive Manufacturing), to practice new design concepts (BESO).

\subsubsection{Proposal 1: Chitosan-Cellulose Based Biomaterial (Fig. 4)}

CELLULOSE and CHITON is the 1st and 2nd abundant substance in nature, which means significantly potential for architectural dimension production. Meanwhile, the mechanic properties can be enhanced with certain additives, such as pectin, Xanthan Gum, or even recycled paper fiber. Moreover, the printability of the mixture makes it possible to cooperate with robotic 3D printing.

\subsubsection{Proposal 2: Large Scale Robotic 3D-Printing (Fig. 5)}

A proper fabricating method is strongly required once we have the proper biomaterial for architectural application. The way of this thesis focusing on is large scale robotic 3D printing. This kind of biomaterial can be used in a traditional manufacturing way, such as model casting. But with the help of robotic $3 \mathrm{D}$ printing, we can significantly speed up the construction efficient and achieve a more organic form. 


\subsubsection{Proposal 3: Bidirectional Evolutionary Structural Optimization [3] (Fig. 6)}

Once we decide the material and the fabrication method, we need to think about how we should design accordingly. This thesis is trying to explore the biomaterial application in architectural scale, which means it should be a structure part, like a beam or pillar. With the idea of BESO, we can figure out a reasonable and organic result.

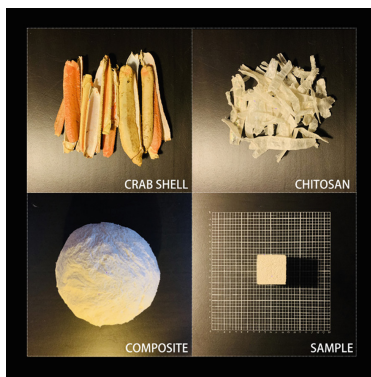

Fig. 4. Proposal 1

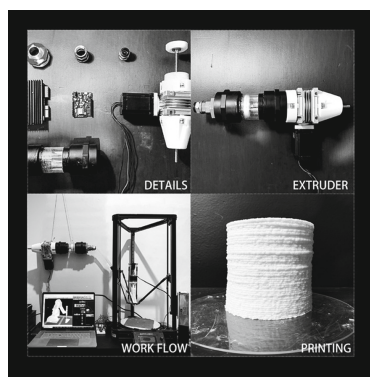

Fig. 5. Proposal 2

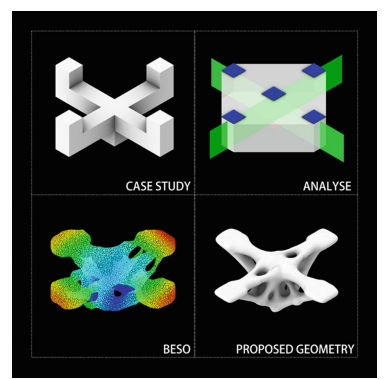

Fig. 6. Proposal 3

\section{Experimental Procedure}

\subsection{Micro_Intermolecular Mechanism and Reaction}

\subsubsection{Cellulose Based Biomaterial Innovation}

From the case study, we learned that Chitosan will combine all the fiber-like substances such as cellulose, wood fiber or paper fiber during the crystallization reaction. But also, even in the most proper ratio, such as 1:8 (chitosan : pure cellulose), Chitosan and Cellulose mixture will not have the proper mechanical strength for architectural structure application. In this MICRO state research, we gonna explore several additives to make an innovation to pure chitosan- cellulose composite. The aim is to enhance the strength and reduce the shrinkage.

\subsubsection{Intermolecular Mechanism_Optical Microscope Observation Research}

We made Chitosan solution ( $1 \mathrm{~g}$ chi in $1 \% \mathrm{w} / \mathrm{w}$ acetic acid) as the base reference of MICRO level research. First, the molecule is all separate when there is only chitosan (Fig. 7), but once we add cellulose inside (Fig. 8), the molecule starts to turn to combine reactions (Fig. 9).

From here we can see the chitosan solution will combine all the fiber-like substances during the Crystallization reaction. Just like concrete and rebar, This is the basement of why chitosan-cellulose based biomaterial has remarkable mechanical properties.

\subsection{Meso _ Material Innovation and Properties Experiments}

\subsubsection{Additives Research}

In order to strengthen specific characters of Cellulose-Chitosan composite, additives will be necessary. The current problem of pure composite is mainly low mechanical strength 


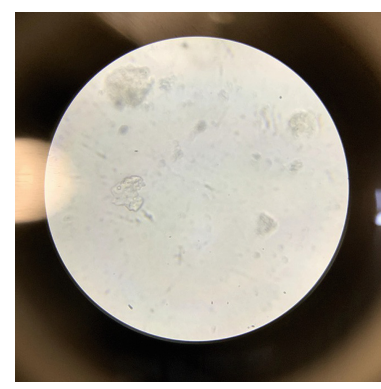

Fig. 7. Cellulose only (1g chi in $1 \% \mathrm{w} / \mathrm{w}$ acetic acid)

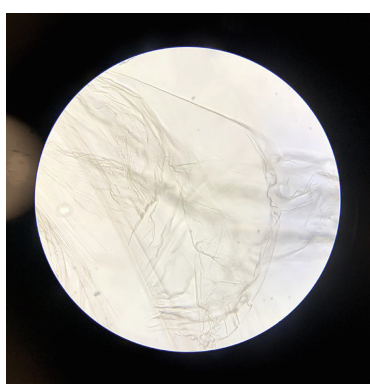

Fig. 8. Cellulose with chitosan $(1 \mathrm{~g}$ chi in $1 \% \mathrm{w} / \mathrm{w}$ acetic acid)

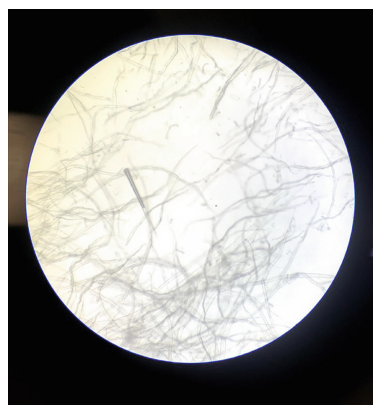

Fig. 9. Paper fiber with chitosan (1g chi in $1 \% \mathrm{w} / \mathrm{w}$ acetic acid)

and heavy drying shrinkage. To optimise these problems, we have to look into certain additives [5].

\section{The Optional Additives}

Gelatine: To increase the mechanical strength and speed up the solidification process. Xanthan Gum: To make the composite more stable and homogeneous, and more suitable for printing.

Glycerin: To enhance flexibility and generate bio-plastic. it might not be structure but other architecture parts.

Flour: to decrease the dry shrinkage.

Paper Fiber: to decrease the dry shrinkage and enhance mechanical strength.

Pine Resin: to speed up the solidification process.

\section{Experiment Recording (Fig. 10)}

Sample 01: $1 \mathrm{~g}$ cellulose $+1 \mathrm{~g}$ chitosan $(1 \mathrm{~g}$ chitosan in $1 \% \mathrm{w} / \mathrm{w}$ acetic acid $)$

Sample 02: $1 \mathrm{~g}$ cellulose $+1 \mathrm{~g}$ gelatine $+1 \mathrm{~g}$ chitosan $(1 \mathrm{~g}$ chitosan in $1 \% \mathrm{w} / \mathrm{w}$ acetic acid)

Sample 03: $1 \mathrm{~g}$ cellulose $+1 \mathrm{~g}$ glycerin $+1 \mathrm{~g}$ chitosan $(1 \mathrm{~g}$ chitosan in $1 \% \mathrm{w} / \mathrm{w}$ acetic acid)

Sample 04: $1 \mathrm{~g}$ cellulose $+1 \mathrm{~g}$ Xanthan Gum $+1 \mathrm{~g}$ chitosan $(1 \mathrm{~g}$ chitosan in $1 \% \mathrm{w} / \mathrm{w}$ acetic acid)

Sample 05: $1 \mathrm{~g}$ cellulose $+1 \mathrm{~g}$ Pine Resin $+1 \mathrm{~g}$ chitosan $(1 \mathrm{~g}$ chitosan in $1 \% \mathrm{w} / \mathrm{w}$ acetic acid)

Sample 12: $1 \mathrm{~g}$ cellulose $+1 \mathrm{~g}$ flour $+1 \mathrm{~g}$ paper fiber $+1 \mathrm{~g}$ chitosan $(1 \mathrm{~g}$ chitosan in $1 \% \mathrm{w} / \mathrm{w}$ acetic acid) 


\section{Summary}

By setting up a control group experiment, we find some additives can greatly optimise the properties of chitosan- cellulose composite. Xanthan Gum will make the mixture more stable and easier for printing. Flour will enhance the mechanical strength and reduce the dry shrinkage. Paper fiber can significantly reduce the dry shrinkage since it offers a macro level fiber system to cooperate the micro level (cellulose).

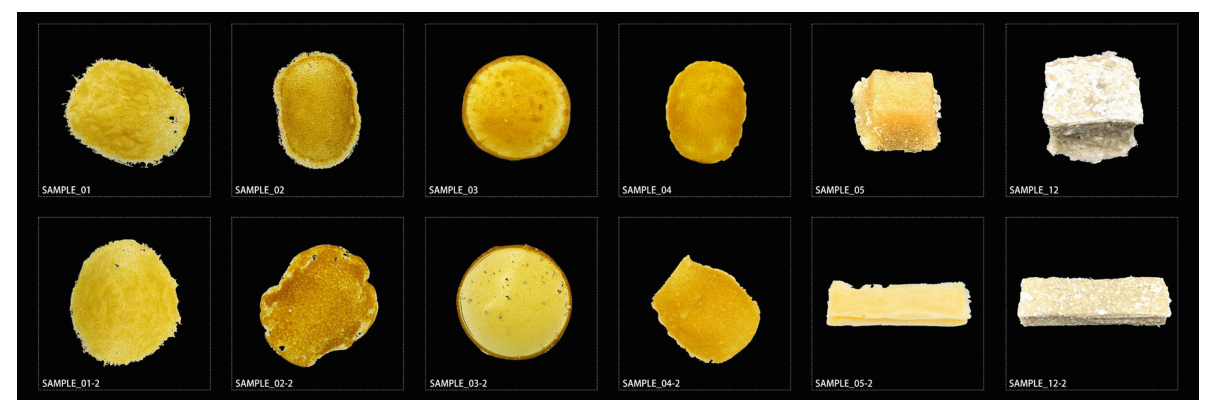

Fig. 10. Sample 01-12

\subsubsection{Ratio Research}

A proper ratio is necessary for this kind of composite to reach the best operating state. From the case study we learned that the most reasonable ratio of Chitosan : Cellulose is $1: 8$. But according to my experiments, this number will significantly change if the type of cellulose is different.

\section{The Optional Cellulose}

Carboxymethyl cellulose: 1:12

Microcrystalline cellulose: 1:10

Nano fiber cellulose: 1:8

Pure fiber cellulose: $1: 8$

Lignocellulosic: 1:6

\section{Observation}

To reach a similar density and viscosity, different cellulose required different ratios [6]. 
As is mentioned above, the ratio can be significantly different once the type of cellulose changed. Basically, the ratio will grow higher when the fiber size grows smaller.

\section{Experiment Recording (Fig. 11)}

Sample 13: $10 \mathrm{~g}$ cellulose $+1 \mathrm{~g}$ flour $+1 \mathrm{~g}$ Xanthan Gum $+10 \mathrm{~g}$ paper fiber $+1 \mathrm{~g}$ chitosan

Sample 14: $8 \mathrm{~g}$ cellulose $+1 \mathrm{~g}$ flour $+1 \mathrm{~g}$ Xanthan Gum $+8 \mathrm{~g}$ paper fiber $+1 \mathrm{~g}$ chitosan

Sample 15: $6 \mathrm{~g}$ cellulose $+1 \mathrm{~g}$ flour $+1 \mathrm{~g}$ Xanthan Gum $+6 \mathrm{~g}$ paper fiber $+1 \mathrm{~g}$ chitosan

Sample 16: $8 \mathrm{~g}$ cellulose $+1 \mathrm{~g}$ flour $+2 \mathrm{~g}$ Xanthan Gum $+8 \mathrm{~g}$ paper fiber $+1 \mathrm{~g}$ chitosan

Sample 19: $8 \mathrm{~g}$ cellulose $+3 \mathrm{~g}$ flour $+1 \mathrm{~g}$ Xanthan Gum $+8 \mathrm{~g}$ paper fiber $+1 \mathrm{~g}$ chitosan

Sample 20: $8 \mathrm{~g}$ cellulose $+2 \mathrm{~g}$ flour $+1 \mathrm{~g}$ Xanthan Gum $+8 \mathrm{~g}$ paper fiber $+1 \mathrm{~g}$ chitosan (Sample 13-20: 1G CHITOSAN IN 3\%W/W ACETIC ACID)

\section{Summary}

According to the sample testing result, the best ratio for now is $8 \mathrm{~g}$ cellulose $+2 \mathrm{~g}$ flour $+1 \mathrm{~g}$ Xanthan Gum $+8 \mathrm{~g}$ paper fiber $+1 \mathrm{~g}$ chitosan. In this state the shrinkage is min and the printability is the best.

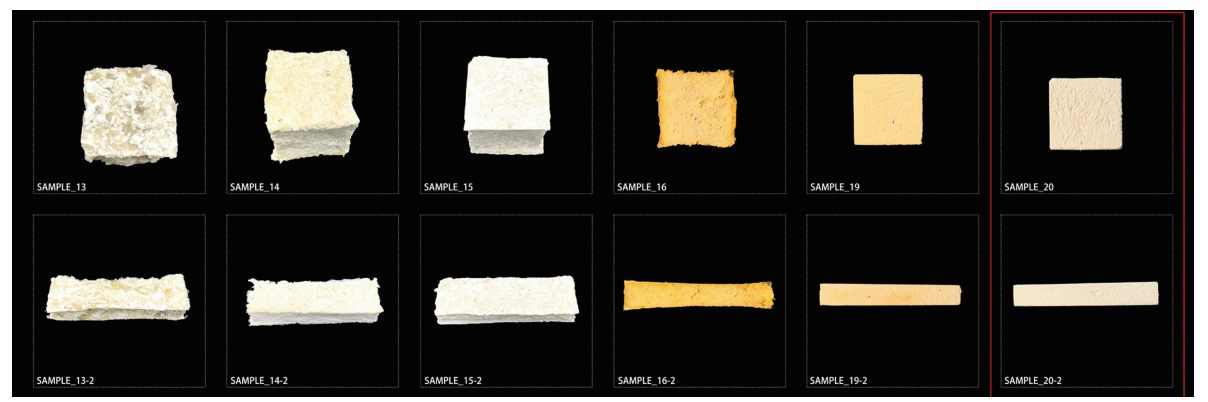

Fig. 11. Sample 13-24 


\subsubsection{Properties Test}

Lightweight Test Based On Water Absorption And Evaporation (Fig. 12): When we finished the material making process, we got a wet, printable composite. Here is an experiment of how much the weight will reduce after it dries. We made 6 groups of samples, weighed it before and after it dry, calculating the weight change.

Conclusion: $70 \%$ weight lost after dry. This kind of material has a significant advantage for architectural application, that it is super light material.

Shrinkage Test (Fig. 13): There is a problem for all biomaterial shrinkage. After dry, the cell structure loses water, and the original form can never be maintained. Here we also create 6 groups for this testing. We measure and record the size in 3 dimensions before and after it dry, and calculate the shrinkage rate.

Conclusion: Around 5\% size shrinkage after it dries. This is an average number. During the testing we noticed the shrinkage direction and size can be slightly different on one sample in different positions. Meanwhile, the model material and the dry environment will significantly influence the result, which means a proper way to do the drying process is the key to control shrinkage and final form.

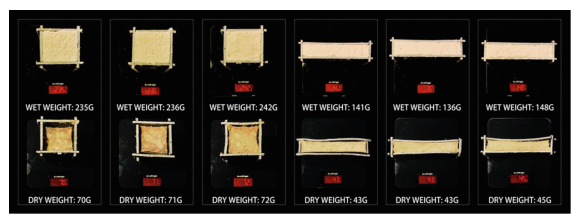

Fig. 12. Lightweight test based on water absorption and evaporation

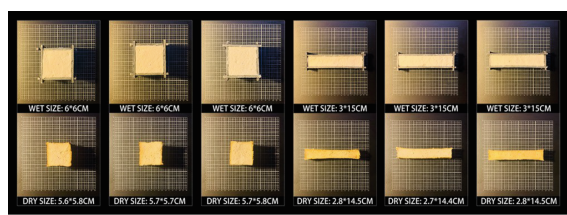

Fig. 13. Shrinkage test

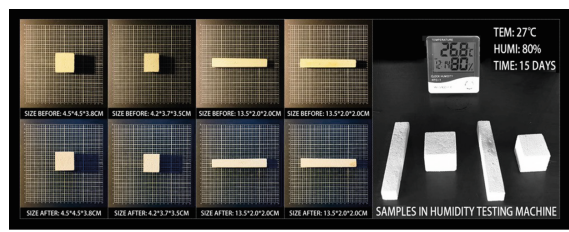

Fig. 14. Moisture test 


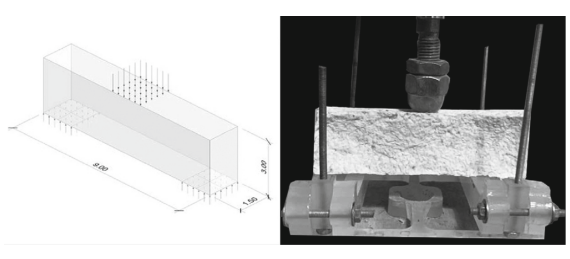

Fig. 15. Compression test

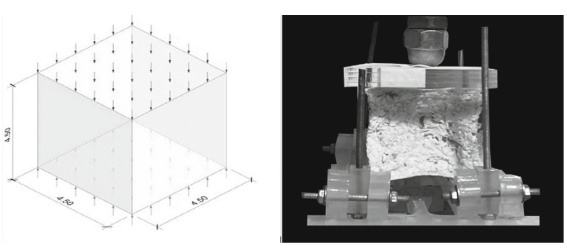

Fig. 16. Bending test

Moisture Test (Fig. 14): Here we also create 4 groups $r$ oisture testing. We measure and record the size in 3 dimensions for all samples and put them in the testing box, with the temperature setting in 27, humidity in $80 \%$ and put them there for 2 month. Every 15 days we measure the size and calculate the deformation ratio.

Conclusion: The deformation is $0 \%$. According to the testing result there is no significant deformation on the testing sample. This means, at least for form keeping, this kind of material is quiet humidity resistant.

Compression and Bending Test (Fig. 15/Fig. 16): Here we use the air pressure device to do the compression and bending testing. This device is developed by IAAC and the maximum air pressure is $8 \mathrm{pa}$. We put one full dried cubic sample for compression and bending testing. When the air pressure goes to the max there is still nothing happening to the sample. After that we tried to put weight on the sample to reach the compression/ bending limitation, but even $100 \mathrm{~kg}$ weight on it there is still not even one crack on surface.

The air pressure testing calculation is based on the following formular:

$\mathrm{F}=\mathrm{P}$ (pressure in bars) $*$ Area (related to piston

diameter in $\mathrm{cm}^{2}$ )

$$
\begin{aligned}
& \mathrm{F}=\mathrm{p} * \mathrm{~A}<=>\mathrm{F}=\mathrm{P} *\left\{\pi * 1.6^{2}\right\}<=>\mathrm{F}=(\mathrm{P} * 8.03) \mathrm{kg} \\
& \mathrm{R}_{\mathrm{TF}}=(3 * \mathrm{~F} * \mathrm{~L}) /\left(2 * \mathrm{~b} * \mathrm{~h}^{2}\right)
\end{aligned}
$$

Conclusion: The compression/bending resistance is remarkable. According to the formula calculating we figured out the number is $>10 \mathrm{~N} / \mathrm{mm}^{2}$, which is a significant advantage for the application in architecture, especially for the architectural part. 


\subsubsection{Data Recording}

Here is the data recording for all the sample testing. From the Sample 2 we figured out that Xanthan Gum is super important for viscosity. From Sample 3 we found flour influences consistency a lot. From Sample 4 we learned that Paper fiber is the key to control the shrinkage.

As for ratio testing recording, from sample 13 we found the best ratio for chitosan and microcrystalline cellulose is 1:10. From Sample 14-17 we learned the amount of xanthan gum and flour is 1:2. And finally, in sample 20, we got the best ratio of this kind of Chitosan-Cellulose base biomaterial composite.

\subsubsection{Summary of Each Additive's Fuction}

1. Cellulose and chitosan will do fibrosis reaction, which is the key to produce stable composite material.

2. Xanthan Gum makes composite more stable and against shrinkage transformation.

3. Gelatin will build up the strength of composite but also increase the shrinkage.

4. Glycerine works as the plasticizer, and will make composite more flexible and against shrinkage transformation.

5. Paper fiber can be great helpful for shrinkage.

6. Flour can cooperate with paper fiber and make the composite more exquisite.

7. Paper fiber mixture is hard to become homogeneous.

8. Cooking will help the fibrosis reaction but will also make composite heterogeneous.

9. Shrinkage will be severe while there is water in the composite but no Hydration reaction. 


\begin{tabular}{|c|c|c|c|c|c|c|c|c|c|c|c|c|c|c|c|c|c|c|c|c|}
\hline 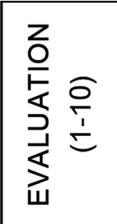 & 0 & $\wedge$ & $\infty$ & $\sigma$ & 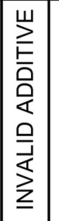 & 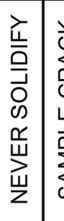 & 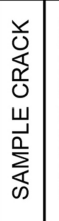 & 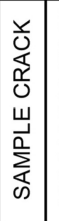 & 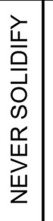 & - & $m$ & 0 & $\wedge$ & 0 & $\lambda$ & $\infty$ & o & \begin{tabular}{|l|}
10 \\
0
\end{tabular} & $\infty$ & 음 \\
\hline \multirow{8}{*}{ 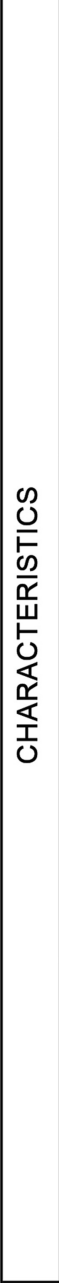 } & 足 & 今े & ○े & ○े & ஃ̊ㅜ & 1 & 1 & 1 & & 今े & 产 & 今̊ & 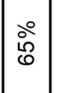 & ठे & ๖े & ठें & 今े & \begin{tabular}{|l|} 
\\
0 \\
0
\end{tabular} & ○े & ठ̊ㅇ \\
\hline & 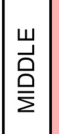 & \begin{tabular}{|l|}
$I$ \\
I \\
$I$ \\
\end{tabular} & \begin{tabular}{|l|}
$\frac{I}{\mathrm{O}}$ \\
$\frac{\mathrm{O}}{T}$ \\
\end{tabular} & \begin{tabular}{|l}
$\frac{T}{O}$ \\
O)
\end{tabular} & \begin{tabular}{|l}
$\frac{I}{\mathrm{O}}$ \\
II
\end{tabular} & 1 & בे & בె & & 30 & 弪 & 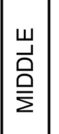 & 岁 & 芆 & $\frac{I}{\underline{I}}$ & \begin{tabular}{|l}
$\frac{I}{\mathrm{O}}$ \\
$\stackrel{\mathrm{O}}{I}$
\end{tabular} & \begin{tabular}{|l|} 
\\
\\
\end{tabular} & \begin{tabular}{|l|}
$\frac{I}{\mathrm{O}}$ \\
$\frac{\mathrm{O}}{\bar{T}}$ \\
\end{tabular} & 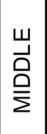 & $\frac{T}{\mathrm{O}}$ \\
\hline & $\begin{array}{l}3 \\
0 \\
0 \\
\end{array}$ & 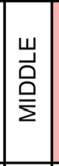 & \begin{tabular}{|l|}
$\frac{\mathrm{I}}{\mathrm{O}}$ \\
$\mathrm{O}$ \\
\end{tabular} & $\begin{array}{l}\frac{T}{O} \\
\text { I }\end{array}$ & \begin{tabular}{|l}
$\frac{I}{J}$ \\
I \\
\end{tabular} & & בे & בె & & 芆 & 辛 & 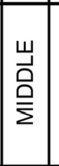 & \begin{tabular}{|l|}
$\frac{I}{O}$ \\
$\stackrel{O}{I}$ \\
\end{tabular} & \begin{tabular}{|l}
$\frac{I}{D}$ \\
$\stackrel{D}{I}$
\end{tabular} & 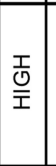 & \begin{tabular}{|l}
$\frac{I}{\mathrm{O}}$ \\
$\stackrel{\underline{I}}{I}$
\end{tabular} & 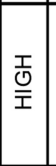 & \begin{tabular}{|l|}
$\frac{I}{O}$ \\
$\frac{O}{T}$ \\
\end{tabular} & 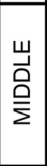 & 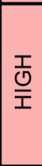 \\
\hline & $\mid \begin{array}{l}3 \\
0 \\
0 \\
\end{array}$ & 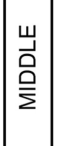 & 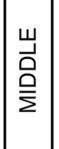 & \begin{tabular}{|l}
$\frac{T}{O}$ \\
O⿱
\end{tabular} & \begin{tabular}{|l}
$\frac{I}{0}$ \\
I \\
\end{tabular} & 1 & & 1 & & 永 & 辛 & 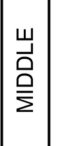 & 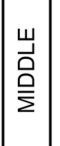 & 3) & 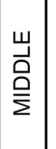 & $\begin{array}{l}\frac{T}{I} \\
\frac{O}{I} \\
\end{array}$ & $\begin{array}{l}\frac{T}{J} \\
\stackrel{O}{T} \\
\end{array}$ & \begin{tabular}{l|}
$\frac{I}{I}$ \\
$\stackrel{O}{I}$ \\
\end{tabular} & 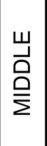 & 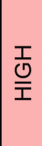 \\
\hline & 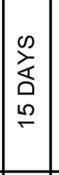 & 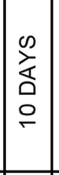 & $\mid \begin{array}{l}0 \\
\text { a } \\
0 \\
0 \\
0\end{array}$ & $\mid \begin{array}{l}0 \\
2 \\
0 \\
0 \\
0 \\
0\end{array}$ & \begin{tabular}{|l}
0 \\
\multirow{2}{0}{} \\
0 \\
0 \\
0
\end{tabular} & 1 & & 1 & & $\mid \begin{array}{l}0 \\
2 \\
0 \\
0 \\
20 \\
\end{array}$ & $\mid \begin{array}{l}0 \\
2 \\
0 \\
0 \\
0 \\
0\end{array}$ & 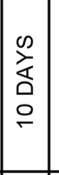 & 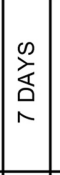 & \begin{tabular}{|l|}
$\infty$ \\
$\grave{z}$ \\
$\Delta$ \\
$\Lambda$ \\
$\Lambda$
\end{tabular} & $\mid \begin{array}{c}0 \\
\grave{Z} \\
\Delta \\
\wedge \\
\wedge\end{array}$ & 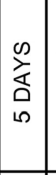 & $\mid \begin{array}{l}0 \\
Z \\
0 \\
0 \\
0\end{array}$ & \begin{tabular}{|l|}
0 \\
$z$ \\
$\vdots$ \\
0 \\
0
\end{tabular} & 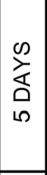 & 年 \\
\hline & ठ̊ㅇ & 高 & 总 & @응 & 은 & 1 & 1 & 1 & I & ㅇํㅇ & 今ั & ஓ̊̀ & ठें & ठें & ০ें & 今े & ○े & ○े & iे & i̊ \\
\hline & $\left|\begin{array}{c}\tilde{z} \\
\xi \\
\xi \\
z \\
o \\
o \\
\tilde{c} \\
0\end{array}\right|$ & 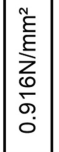 & $\left|\begin{array}{l}\tilde{z} \\
\underline{\xi} \\
\underline{\xi} \\
z \\
0 \\
\tilde{D} \\
\tilde{m} \\
\tilde{c}\end{array}\right|$ & 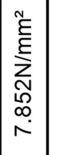 & 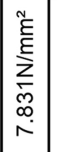 & 1 & 1 & 1 & 1 & 1 & 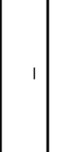 & 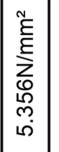 & $\left|\begin{array}{c|}\tilde{c} \\
\xi \\
\bar{\xi} \\
\infty \\
\vdots \\
0 \\
\dot{0}\end{array}\right|$ & 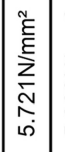 & 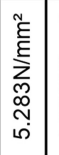 & 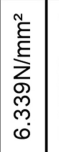 & 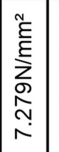 & 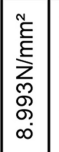 & 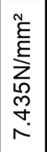 & 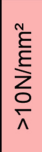 \\
\hline & $\left|\begin{array}{c}\tilde{z} \\
\xi \\
\xi \\
z \\
\tilde{N} \\
\tilde{J} \\
\dot{\sigma} \\
0\end{array}\right|$ & $\left|\begin{array}{c}\tilde{z} \\
\xi \xi \\
\xi \\
o \\
o \\
\tilde{g} \\
\dot{0} \\
0\end{array}\right|$ & 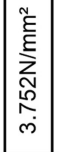 & 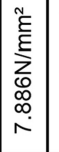 & 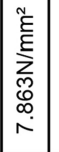 & 1 & & 1 & 1 & 1 & 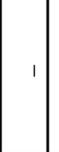 & 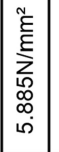 & $\left|\begin{array}{c}\tilde{c} \\
\underline{\xi} \\
\underline{z} \\
\tilde{N} \\
\tilde{J} \\
\dot{0}\end{array}\right|$ & 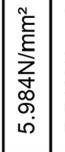 & 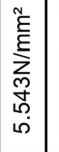 & 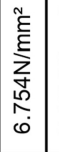 & 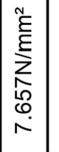 & 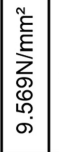 & 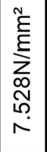 & 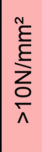 \\
\hline$\sum_{\underline{E}}^{\infty}$ & 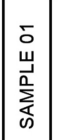 & 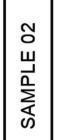 & 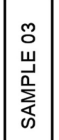 & 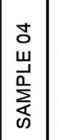 & 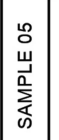 & 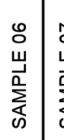 & 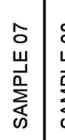 & 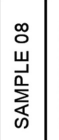 & 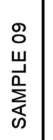 & 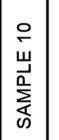 & 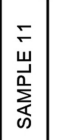 & 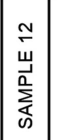 & 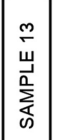 & 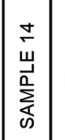 & 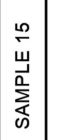 & 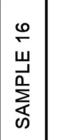 & 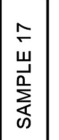 & 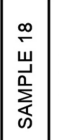 & 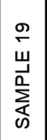 & 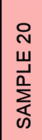 \\
\hline
\end{tabular}




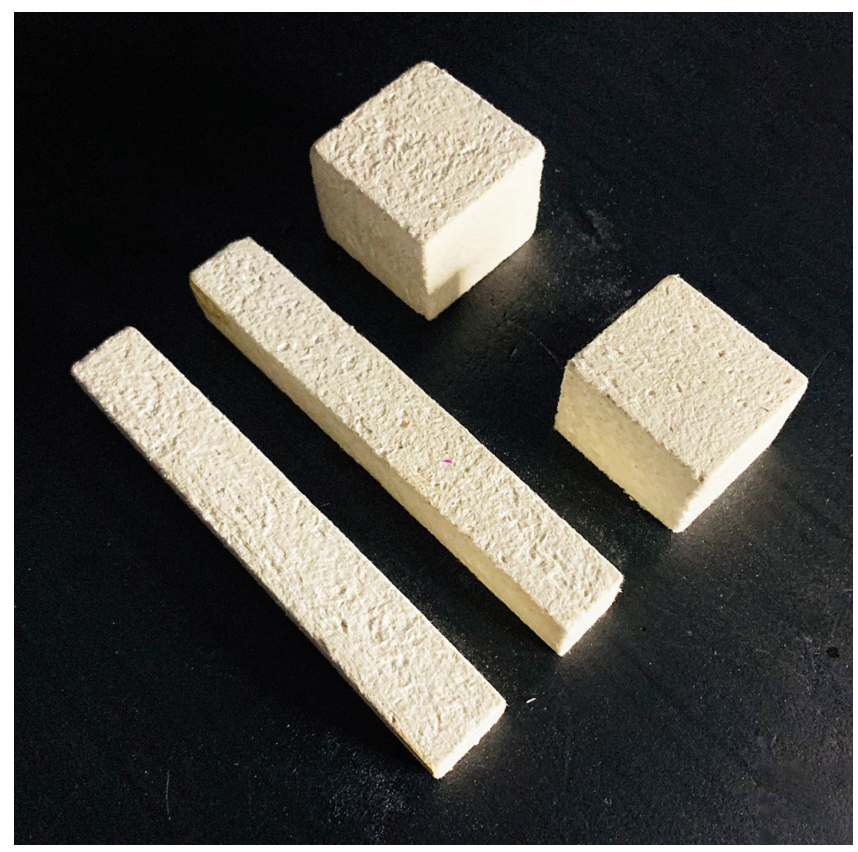

Fig. 17. Sample 20 parameters: Dry time: $48 \mathrm{~h}\left(80^{\circ} \mathrm{C}\right) / 7$ days $\left(25^{\circ} \mathrm{C}\right)$, Lighting weight: $60 \%-70 \%$, Shrinkage: $5 \%$, Humidity resistance: $0 \%$, deformation: $(80 \%$ hum $/ 2 \mathrm{w})$, Compression resistance: $>10 \mathrm{n} / \mathrm{mm}^{2}$, Bending resistance: $>10 \mathrm{n} / \mathrm{mm}^{2}$, Biodegradability: $100 \%$, Recyclability: $100 \%$

\subsection{Macro_Architectural Scale Application}

\subsubsection{Geometry Design-Research Strategy}

This part is focusing on the application of biomaterial on architectural structure. Here we assumed a specific pavilion structure, and used ameba to do the beso analysis to figure out the most reasonable state of all the bearing elements, and thereby generated the skeleton of this pavilion (Fig. 20).

This process is focusing on the combination of the advantages of BESO and Additive Manufacture (like robotic 3D printing on architectural scale), and the possibility of Advanced Architecture Design- Construction Workflow which is super different from the Traditional Construction Methods.

BESO is a form-finding theory developed by Ameba research team, the leader is Xie Yimin, from RMIT. Ameba is a plug-in software based on Grasshopper.

Here in the following chart (Fig. 18), we can see the iteration information and the analysing state. Finite element is growing fewer and fewer while the Total energy is growing higher and higher. The result of analysis can be displayed in real time once there is an updated calculation (Figs. 19 and 20). 


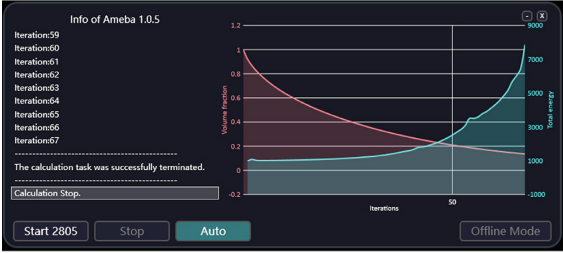

Fig. 18. Iteration information

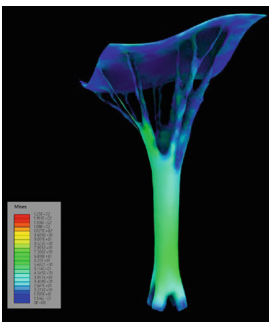

Fig. 19. MISES diagram.

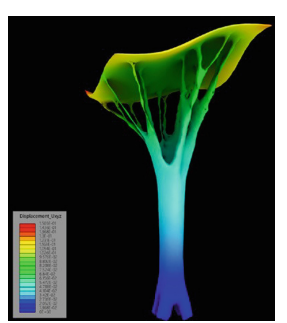

Fig. 20. Displacement diagram.
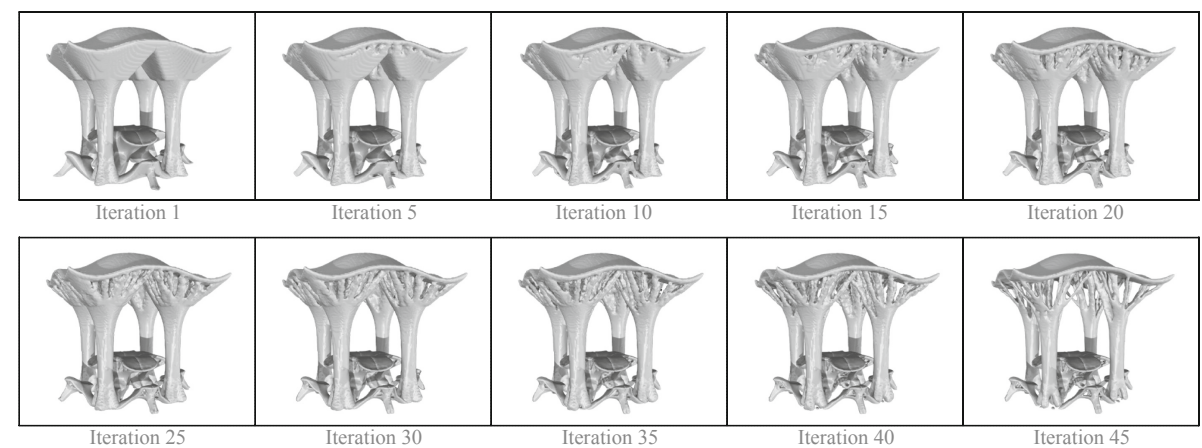

Fig. 21. Generation process

\subsubsection{Generation Process}

Here we have the BESO analysis interaction (Fig. 21). there is 45 times interaction in total. We recorded here every 5 Iterations. BESO is an analysis system based on Finite element. In each iteration it will automatically remove some low-efficient elements and put more elements in the weak part.

The left elements will grow fewer and fewer since the iteration is building up. Usually when we do the architectural analysis, the iteration will meet up the most reasonable state when the iteration comes to 40-60.

Here in this tree pavilion design (Fig. 22), at the iteration of 45 we got the ideal analysis result. The next step is to modify this basic form accordly, and optimise it into a more logic, smooth state that can be fabricated.

\section{Additive Manufacture}

\subsection{PC - Extruder - 3D Printer Workflow and Extruder Fabrication}

In the early stage of Bio-material printability test, we developed a small-scale printer suit based on ANYCUBIC KOSSEL 3D printer. This series of processing equipment can fully meet the printing requirements of pneumatic/motorized extrusion and continuous breakpoint printing, and the small size is suitable for house office. 


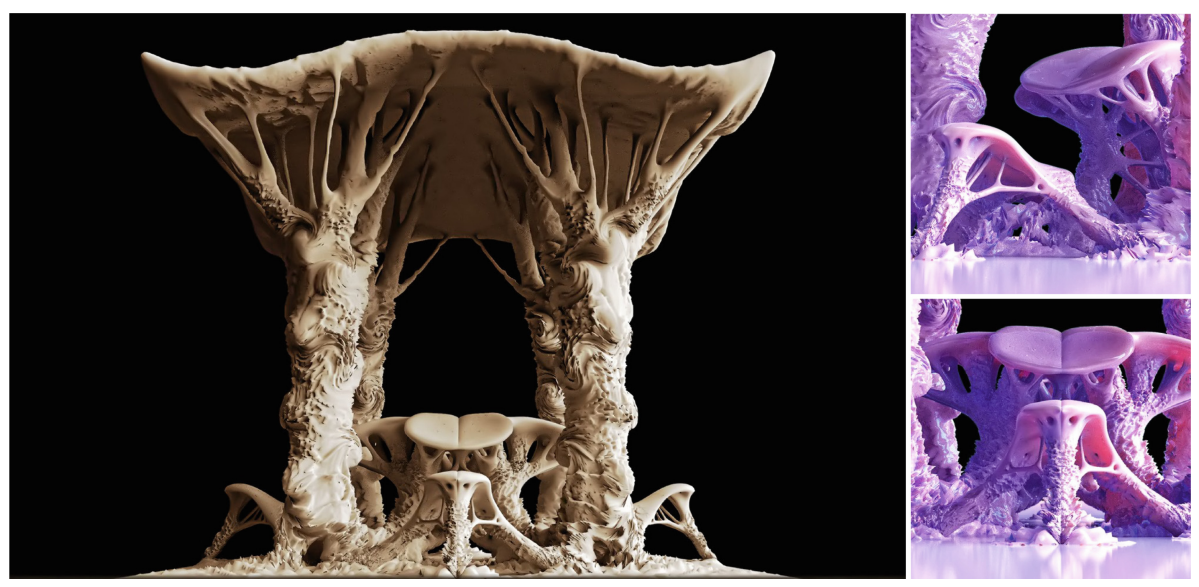

Fig. 22. Tree pavilion

\subsubsection{Delta Extruder (Fig. 23)}

This delta extruder is developed for small scale 3D printing. The Function of this device is mainly to make sure that there is no bubble inside the material, instead of pushing material out.

To make sure the material comes out in the right direction instead of goes up, we put two bearing washers to clap the bearing.

\subsubsection{Robotic Extruder (Fig. 24)}

This robotic extruder is developed for large scale 3D printing. The length of the material tube is $60 \mathrm{~cm}$, which means the printing distance is remarkable.

To make sure the step motor outputs the right speed to cooperate the motivation of the robot arm, we add a gearbox to match the speed.

\subsection{Biomaterial Printability Testing}

This part is printing testing with biomaterial. There are three different testing aspects: First is the extrudability of biomaterial. Secondly is the accumulability and Third one is Decline Angle limitation testing.

\subsubsection{Prototype 3D Printing Test Summary}

The operation process is smooth and the stability of the prototype is good. Quantitative analysis of the carrying capacity will be followed up. Based on the current research results, it is initially determined that the cellulose-chitosan-based Biomaterials are feasible for 3D printing structural members in the construction field (Figs. 25, 26 and 27). 


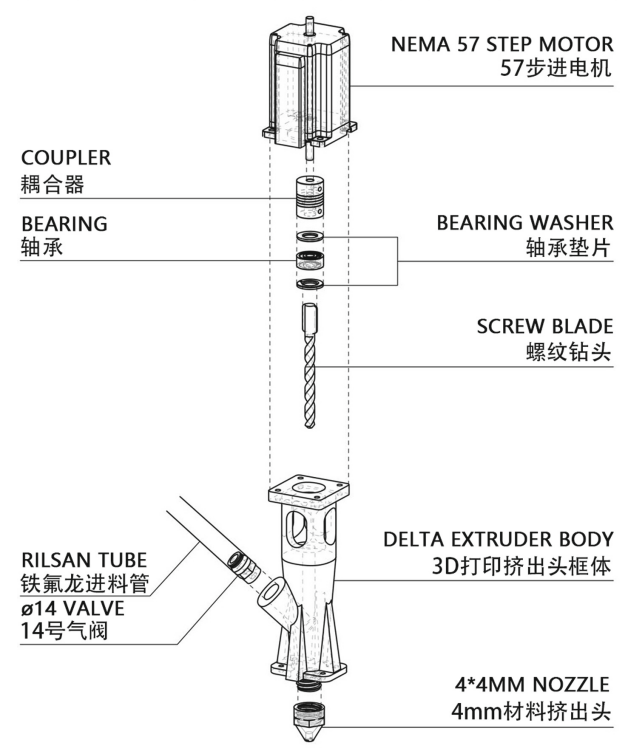

Fig. 23. Delta extruder

\subsubsection{Form Optimization for Large Scale 3D Printing}

\section{Optimization 1 _opening Printing}

Limited by the conditions of the site equipment, this time it was not possible to do opening printing. However, based on the previous printing experience, opening printing can be used for this kind of bio-material (Fig. 28).

\section{Optimization 2 _Decline Angle Limitation}

The angle setting for this test was relatively conservative, and a 40-degree safety angle was selected. However, based on the previous testing results, the upper limit can reach about 60 degrees, thereby creating a more efficient structure (Fig. 29).

\subsubsection{Large Scale 3D Printing Test Summary}

This version is a buildability test conducted in the middle of the design. The selected form is relatively conservative, with a maximum tilt angle of only 40 degrees. In addition, due to the site and equipment conditions during the epidemic and the difficulty of material transportation, the selection of the test material for this time was the cellulose-pla-based ecological material provided by a third party. This material is basically the same as the early composition of this research, and the characters are also relatively close. So using this as an alternative version of the final material, the deviation of the test results will be comparable (Fig. 30). 


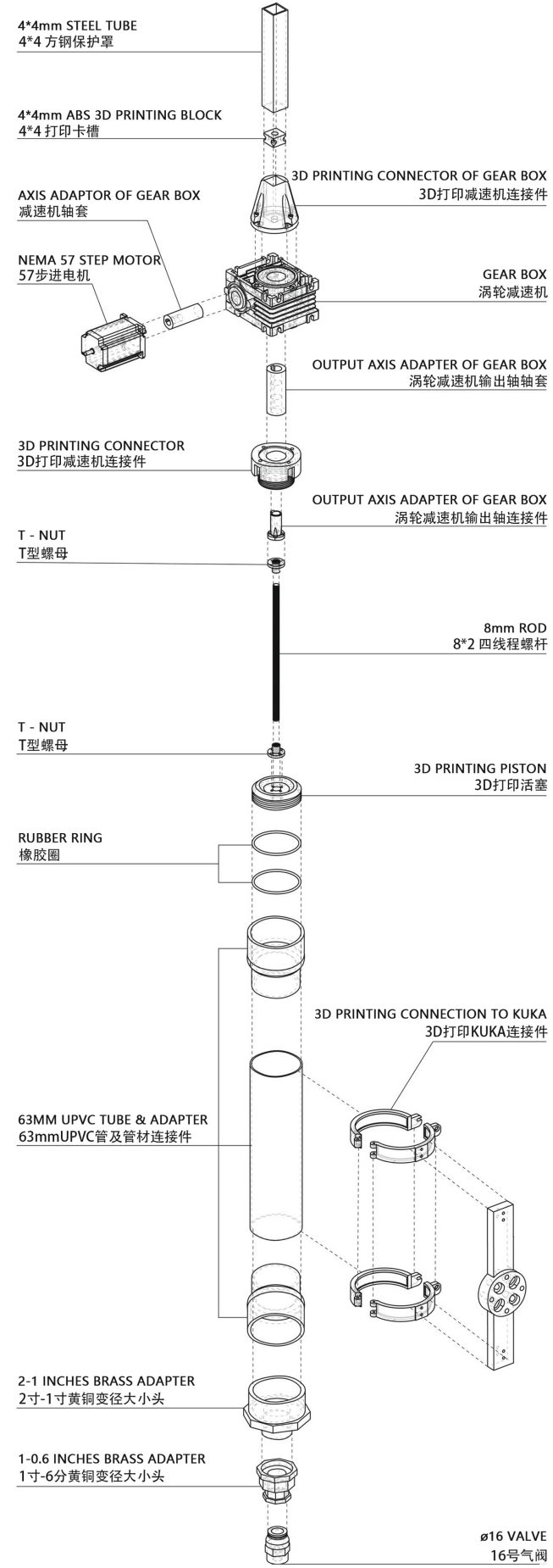

Fig. 24. Robotic extruder 


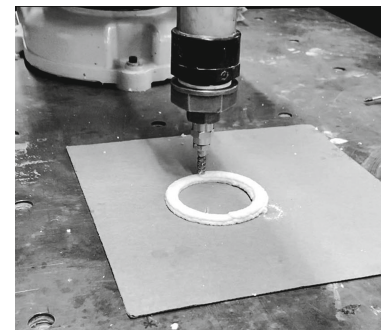

Fig. 25. Extrudability

testing: The extrudability of this kind of material is quite good. According to the air pressure powered extrude testing, the operating gas pressure is $2 \mathrm{pa}$, which means it is quite easy to extrude and the operation condition is quite safe.

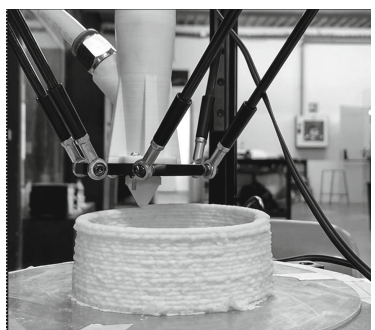

Fig. 26. Accumulability

testing: This testing version is focusing on accumulability of this composite. According to the test result, the accumulability is significant. We accumulated more than 100 layers and it remains super stable.

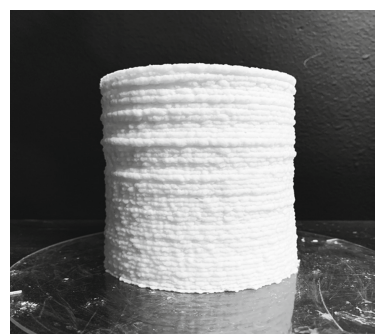

Fig. 27. Decline angel limitation testing: The decline angle limitation testing shows that, while the material is in wet state, the angle limitation is around 20 degree. But once we blow it with hot wind to speed up the water evaporation, the angle limitation is significantly improved.
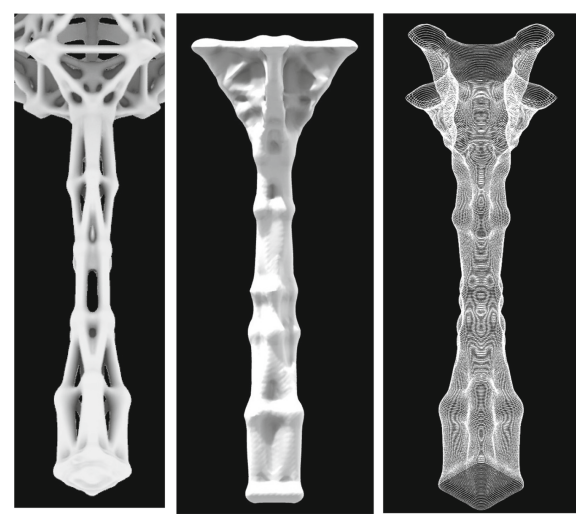

Fig. 28. Large scale form optimization

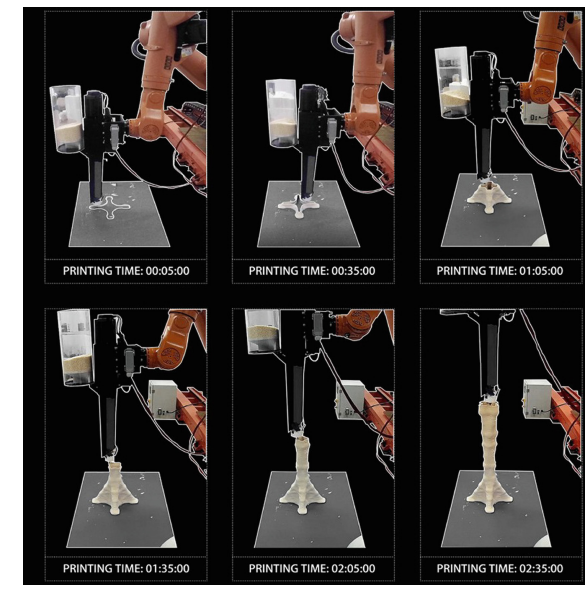

Fig. 29. Printing process 


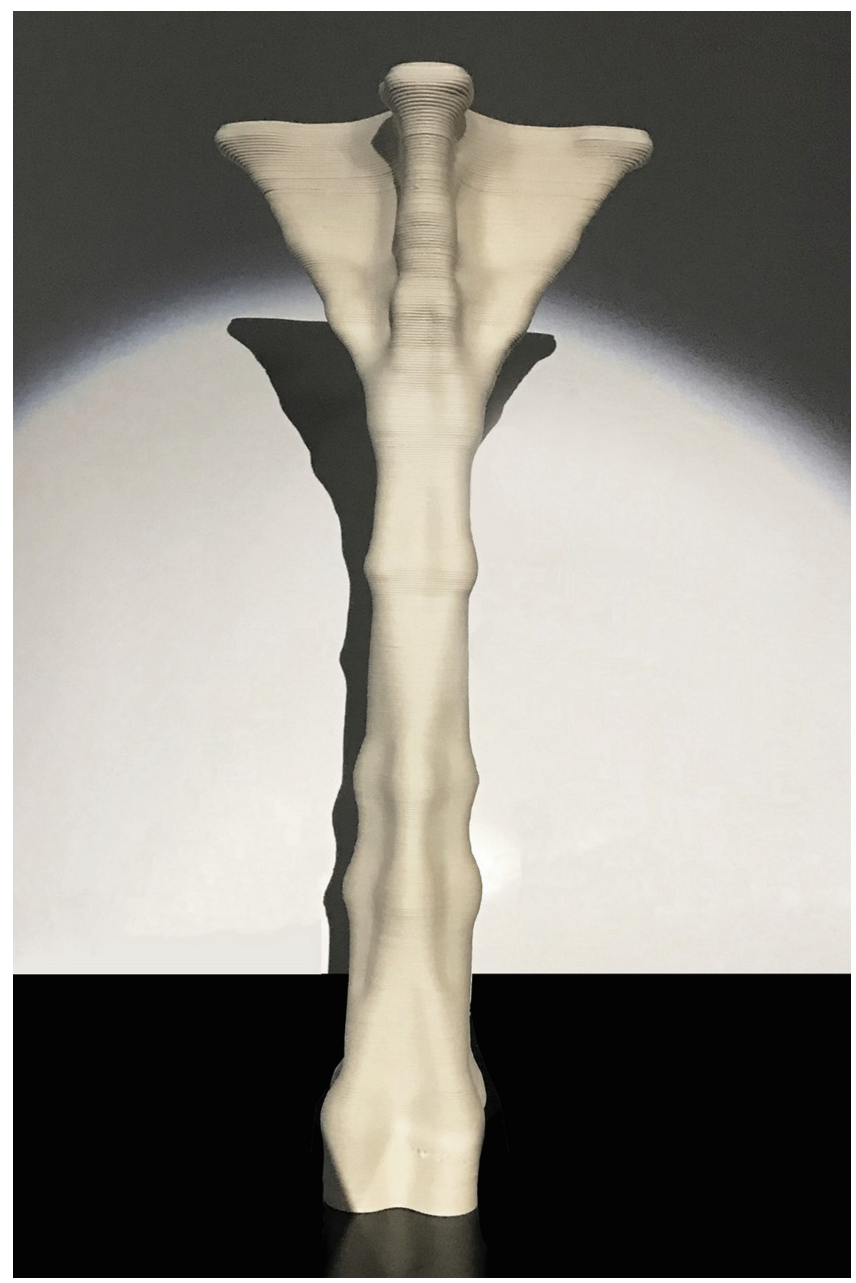

Fig. 30. Printing parameters. Prototype height: $1 \mathrm{~m}$. Max decline angle: $40^{\circ}$ Prototype Weight: $3.25 \mathrm{~kg}$ Total Routine Length: $202 \mathrm{~m}$ Nozzle Diameter: $4 \mathrm{~mm}$ Material Amount: $8080 \mathrm{~cm}$ Printing Time: 6 h $25 \mathrm{~min}$

\section{Conclusion}

\subsection{Combination: Biomaterial + Additive Manufacture + Beso}

This thesis research is focusing on the economic problems and natural issues caused by today's construction industry [7], and coming up with a possible solution in the aspects of Biomaterial, Additive Manufacture and Bi-direnctional Evolutionary Structural Optimisation (BESO). 


\subsubsection{Biomaterial}

Cellulose and chitosan are the first/second abundant materials in this world, with natural characteristics such as biodegradability and renewability. Moreover, this thesis proved the mechanical character [8] can be enhanced or oriented optimised with specific additives [9], which means it is of great potential for architectural application.

\subsubsection{Additive Manufacture}

With the cooperation of a new booming construction ideal, robotic labor and data oriented management, "printed house" is coming to this real world step by step. Additive manufacture is definitely one of the best ways to cooperate with biomaterial. This thesis proofed the possibility of 3D printed biomaterial on architectural scale, which can be a meaningful inspiration for further research.

\subsubsection{BESO}

Here in this thesis, we use BESO as a theory to generate structures. What should be stressed here is just one ideal of many. How do we use new material, as well as fabrication tools and methods, is always a multidisciplinary innovation. it can be BESO, it can be FGM [10], it can be any possible or seems-impossible way. We tried BESO in this thesis because we want to confirm this thinking is possible, and more important, to share an inspiration for further innovation.

Acknowledgments. I would like to express my gratitude to my thesis advisors Areti Markopoulou. This thesis would not be possible without her guidance, dedication and inspirational insides on the intersection of architecture, biology and additive manufacture. I would like to thank Eduardo Chamorro Martin, a genius mechanist, and Nikol Kirova, a worm-heart supervisor and friend. Their support and remarks were quite essential for the development of the thesis.

I would also like to thank Ricardo Mayor for his guidance on digital fabrication, robotics and computation. I would like to thank Ankita Alessandra Bob, Surayyn Selvan and Megan Yates Smylie. Their willingness to give time so generously has been very much appreciated.

Next, I would like to thank Anton Koshelev for his support on robotic extruder. And Seçil Afşar, for her generous sharing of chitosan-cellulose work experience. Also, I would like to express my special gratitude to my Classmate Doruk Yildirim for sharing the in-house knowledge on robotics and additive manufacturing with clay.

Finally, I will be forever grateful to my family and friends who have supported me for the last 9 years throughout different countries and continents, their encouragement has made all this possible.

\section{References}

1. Duro-Royo, J.: Aguahoja_Programmable Water-based Biocomposites for Digital Design and Fabrication across Scales. MIT, pp. 1-3 (2019)

2. Sanandiya, N.D., Vijay, Y., Dimopoulou, M., Dritsas, S., Fernandez, J.G.: Large-scale additive manufacturing with bioinspired cellulosic materials. Sci. Rep. 8(1), 1-5 (2018) 
3. Yan, X., Bao, D.W., Cai, K., Zhou, Y.F., Xie, Y.M.: A New Form-finding Method for Shell Structures Based on BESO Algorithm, pp. 3-6. International Association for Shell and Spatial Structures (IASS), Barcelona (2019)

4. Giachini, G.S., et al.: Additive manufacturing of cellulose-based materials with continuous, multidirectional stiffness gradients. Sci. Adv. 6, 1-4 (2020)

5. Grigoriadis, K.: Computational Blends: The Epistemology of Designing with Functionally Graded Materials. J. Architect. 24, 160-192 (2018)

6. Mogas-Soldevila, L., et al.: Designing the ocean pavilion: biomaterial templating of structural, manufacturing, and environmental performance. In: Future Visions, Amsterdam, pp. 1-6 (2015)

7. Mondello, G., et al.: Life cycle thinking in decision-making for sustainability: from public policies to private businesses. In: Proceedings of the 12th Italian LCA Network Conference, pp.477-452, Messina (2018)

8. Gupta, S.S., et al.: Hygro Assembly. Singapore University of Technology and Design, pp. 2-4 (2019)

9. Markopoulou, A., et al.: PIEL VIVO/BIO-PLASTICA - Material Explorations, pp. 2-14. IAAC, Barcelona (2016)

10. Foroughi, A., et al.: Research of Functionally Graded Materials Manufacturing. IAAC, Barcelona (2018)

Open Access This chapter is licensed under the terms of the Creative Commons Attribution 4.0 International License (http://creativecommons.org/licenses/by/4.0/), which permits use, sharing, adaptation, distribution and reproduction in any medium or format, as long as you give appropriate credit to the original author(s) and the source, provide a link to the Creative Commons license and indicate if changes were made.

The images or other third party material in this chapter are included in the chapter's Creative Commons license, unless indicated otherwise in a credit line to the material. If material is not included in the chapter's Creative Commons license and your intended use is not permitted by statutory regulation or exceeds the permitted use, you will need to obtain permission directly from the copyright holder.

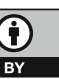

